\title{
The relationships between hypoxia-dependent markers: HIF-1alpha, EPO and EPOR in colorectal cancer
}

\author{
Marek Baltaziak ${ }^{1}$, Andrzej Wincewicz ${ }^{4}$, Luiza Kanczuga-Koda ${ }^{3}$, Joanna M. Lotowska ${ }^{1}$, \\ Mariusz Koda ${ }^{1}$, Urszula Sulkowska ${ }^{3}$, Marcin Baltaziak ${ }^{5}$, Monika Podbielski ${ }^{3}$, \\ Maria E. Sobaniec-Lotowska ${ }^{2}$, Stanislaw Sulkowski ${ }^{1}$
}

\author{
${ }^{1}$ Department of General Pathomorphology, Medical University of Bialystok, Poland \\ ${ }^{2}$ Department of General and Medical Pathomorphology, Medical University of Bialystok, Poland \\ ${ }^{3}$ Department of Diagnostic Histopathology and Cytology, Jedrzej Sniadecki Memorial Hospital, \\ Bialystok, Poland \\ ${ }^{4}$ Department of Anatomy, Faculty of Health Sciences, Jan Kochanowski Memorial University, \\ Kielce, Poland \\ ${ }^{5}$ Department of Rehabilitation, Medical University of Bialystok, Poland
}

\begin{abstract}
Hypoxia triggers production of several cytoprotective proteins. Hypoxia-inducible factor 1alpha (HIF $-1 \alpha$ ) is a powerful stimulator of transcription of many genes, including erythropoietin (EPO) in hypoxia-affected cells. Recent data have also implicated signaling by EPO receptor (EPOR) as a new factor influencing tumor progression. The aim of the study was to detect by immunohistochemistry the presence of HIF- $1 \alpha$, EPO and EPOR in colorectal cancer (CRC) in reference to clinicopathological variables. We found the presence of the studied proteins in specimens of all 125 CRC patients which is suggestive of the occurrence of hypoxia in colorectal cancer tissues. The expression of HIF- $1 \alpha$ correlated significantly with the presence of EPO and EPOR in all samples $(P<0.001, r=0.549$ and $P<0.001, \mathrm{r}=0.536$, respectively). Significant correlations (from $P<0.024$ to $P<0.001$ ) were found in the analyses of CRC subgroups such as histopathological type tumor, tumor grade, tumor stage and patients with lymph nodes metastases. The same high significant correlations $(P<0.001)$ were observed in group of sex, age and tumor location. However, the values of the correlation coefficients (r) which usually ranged from 0.5 to 0.6 suggest the existence of independent or concurrent mechanism stimulating generation of these proteins in colorectal cancer. (Folia Histochemica et Cytobiologica 2013, Vol. 51, No. 4, 320-325)
\end{abstract}

Key words: HIF- $1 \alpha$; EPO; erythropoietin receptor; correlation; colorectal cancer; immunohistochemistry

\section{Introduction}

HIF-1 $\alpha$ (hypoxia-inducible factor 1alpha) is a powerful stimulator of transcription of many genes, including GLUT-1, p53, p21, blc-2, VEGF and erythropoietin (EPO) [1-3]. Through the expression of these effector genes, HIF- $1 \alpha$ allows the cell to survive during hypoxia by stimulating angiogenesis and, in

Correspondence address: M. Baltaziak, Department of General Pathomorphology, Medical University of Bialystok, Poland; tel.: +48 8574859 96, fax: +48 8574859 96; e-mail:drbal@poczta.onet.pl a further perspective, ensures better conditions for oxygen supply. Most probably, the mechanism is also activated in tumor progression and can be associated with the so called "normobaric oxygen paradox". This is a dual mechanism by which oxygen regulates the expression of the HIF-1 $\alpha$ [4].

Erythropoietin is the primary humoral regulator of erythropoiesis, and the reduction in partial pressure of oxygen (hypoxia) in the kidney is by far the strongest factor stimulating its synthesis. It was also demonstrated that EPO can be produced by the same erythrocyte progenitor cells, which can be related to the autocrine and/or paracrine mechanism of erythropoiesis regulation $[5,6]$. EPO and its receptor, EPOR, have 
recently been found to be expressed on several normal non-hematopoietic cells as well as in cancer tissues. Specifically, high expression of EPOR has been found on the surface of endothelial cells and various solid tumors $[7,8]$. EPO production is stimulated by HIF-1 $\alpha$ in response to hypoxia which is a common phenomenon within a neoplastic tumor, usually associated with resistance to treatment, higher tumor aggressiveness and bad prognosis. EPO and HIF- $1 \alpha$ were intensively co-expressed in cervical dysplasias and invasive cervical cancers [9]. EPO seems to play a crucial role in the process of neoangiogenesis, promotion of survival of hypoxic cancer cells and tumor growth. Recent data have also implicated EPO/EPOR signaling as a new factor influencing tumor progression $[10,11]$

There are very few reports on the relations between HIF-1, EPO and EPOR despite the fact that these factors are induced at a common signaling pathway of HIF-1 transcriptional action in cases of tissue oxygen deficiency. We previously indicated that EPO expression determined by immunohistochemistry (IHC) highly correlated with the EPOR expression in colorectal cancer (CRC) [8] and described in detail the changes observed in the expression and location of HIF-1 $\alpha$ in CRC tissue [12]. The objective of the current immunohistochemical study was to assess the correlations between expression of HIF- $1 \alpha$, EPO and EPOR in relation to pTN staging of CRC, its histological type, histological differentiation grade (G), location, as well as age and sex of patients. To our knowledge, this is the first report to present the above correlations in colorectal cancer.

\section{Material and methods}

Our study included tissue samples of surgically removed colorectal cancers from 125 patients. Patients' characteristics have been shown in Table 1. No individual was treated by either radiotherapy or chemotherapy before tumor resection and no one was given rHuEpo before sampling of cancer tissues. Each neoplastic tumor was cut in parallel to the longest axis to obtain at least one complete cross-section 2-3 mm thick. It was then divided into small blocks of 1-1.5 $\mathrm{cm}$ in diameter. In every case we obtained $4-8$ segments of tumor tissue.

Tumor samples were collected immediately after tumor removal, fixed in $10 \%$ buffered formaldehyde solution for $48 \mathrm{~h}$ and then embedded in paraffin blocks at $56^{\circ} \mathrm{C}$. According to standard procedures, $3-5 \mu \mathrm{m}$ thick slides were cut and stained with hematoxylin and eosin (HE). After the diagnosis of colorectal cancer was confirmed, pathological features were determined as AJCC/UICC TNM stage (American Joint Committee on Cancer/International Union Against Cancer Tumor Node Metastasis), histological tumor type (HP) and grade of histological differentiation (G).
Due to a relatively scant number of pT1 cases we included pT1 and pT2 cancers into one group that corresponded with stage A of Dukes system. Also pT3 and pT4 cancers comprised a separate group which belonged to stage B and $\mathrm{C}$ of Dukes classification. This division was justified by expected differences in the prognosis of patients at stage $\mathrm{A}$ as compared with those at $\mathrm{B}$ and $\mathrm{C}$ stages. Moreover, the tumors were also divided into two histopathological types: non mucinous adenocarcinomas and mucinous adenocarcinomas, in which mucin secreting component made up more than $50 \%$ of all microscopically examined cancer fields.

Immunohistochemical methods. Immunohistochemistry was used to investigate colorectal cancer specimens and staining procedures involved antibodies against HIF-1alpha (sc-10790, Santa Cruz Biotechnology, USA; sc-10790), EPO (sc-7956, Santa Cruz Biotechnology, USA; 1:200 dilution) and EPOR (sc-695, Santa Cruz Biotechnology, USA; 1:400 dilution). In order to visualize the antigen-antibody reaction, EnVision (Dako, Glostrup, Denmark) method was applied, using diaminobenzidine (DAB) as a chromogen. Slides were counterstained with hematoxylin. Positive controls were HIF-1 $\alpha$, EPO and EPOR immunoreactive breast cancer tissues [13]. Negative controls were prepared with omission of primary antibodies.

Immunoreactivities were assessed by two independent pathologists in 10 high power fields of each tumor in light microscopy and the mean rate of tumor immunoreactive (positive) cells was counted. The expression grade of the proteins studied was classified with the following scale: 0 (negative cases), less than $10 \%$ of positive cancer cells; $1+, 10-50 \%$ of positive cancer cells; $2+$, over $50 \%$ of positive cells.

Statistical analysis. Spearman rank correlation test was applied to evaluate the relationships of HIF-1alpha with EPO and EPOR among different groups of patients with a level of statistical significance at $P<0.05$.

\section{Results}

\section{Patterns of immunoreactivity of the studied proteins}

The staining for HIF-1 $\alpha$ was found mainly in the cytoplasm of cancer cells in a granular or/and diffuse pattern. Sometimes the protein accumulated close to the nuclear envelope, and only occasionally and discretely appeared in the nuclei of CRC cells (Figure $1 \mathrm{~A}$ and $1 \mathrm{~B})$.

EPO was present mainly in the cytoplasm of the CRC cells in the form of large granules. Its expression was enhanced in the vicinity of the cell nucleus in tumors with high EPO expression (Figure 1C and 1D). The immunoexpression of EPOR was located 

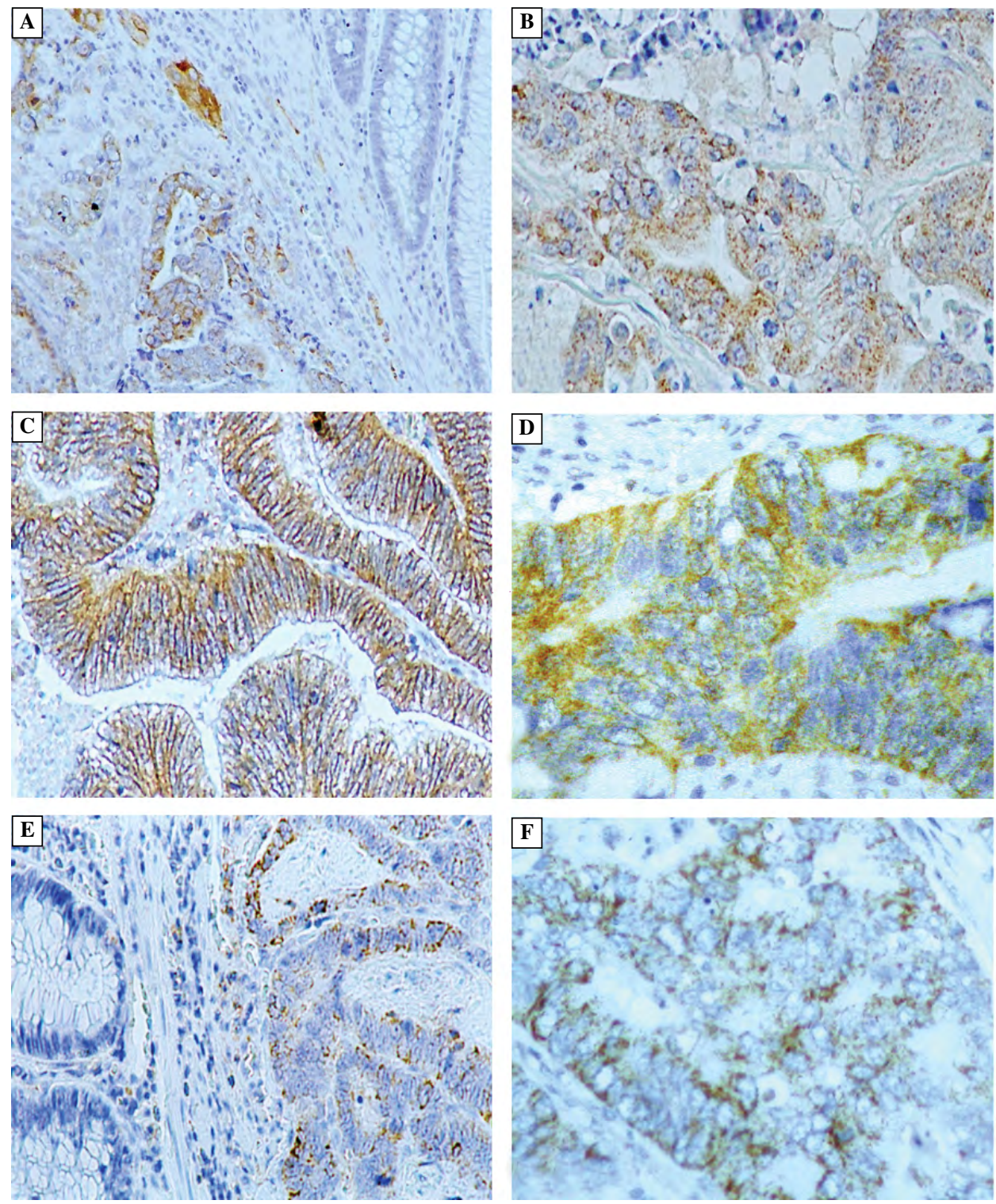

Figure 1. Patterns of cellular distribution of HIF-1 $\alpha$, EPO and EPOR as revealed by immunohistochemistry. A and $\mathbf{B}$. Coarsely granularly distributed immunoreactivity of HIF- $1 \alpha$ (alpha) in cytoplasm of colorectal cancer cells (magnifications: A, $\times 80 ; \mathrm{B}, \times 200)$. C and D. Strong mixed cytoplasmic and membranous deposition of EPO in colorectal cancer cells. Some cells show enhanced accumulation of EPO in perinuclear area $(C, \times 200 ; D, \times 400)$. E and F. Membranous and partly perinuclear staining of bead-like coarse granular pattern for EPOR in colorectal cancer cells $(\mathrm{E}, \times 100 ; \mathrm{F}, \times 400)$

mainly within cell membranes, although in most cases also granular cytoplasmic reaction was observed (Figure $1 \mathrm{E}$ and $1 \mathrm{~F}$ ). In some of the analyzed cases, a weak diffuse cytoplasmic reaction was found, but the staining was considered negative and not taken into account because of the possibility of nonspecific immunohistochemical reactivity [8].

The expression of HIF- $1 \alpha$, EPO and EPOR in $\mathrm{CRC}$ in relation to clinicopathological variables

The immunoreactivity of HIF $1 \alpha$ was statistically highly correlated with the expression of EPO and EPOR in the all of examined groups (Table 1). The statistical analysis of the respective subgroups sho- wed the correlation ( $r$ ) between HIF-1 $\alpha$ and EPO expression to range from 0.475 to 0.678 , and in the case of HIF- $1 \alpha$ and EPOR the values were in the range of $0.426-0.845$. At the same time, we found a very high statistical significance $(P)$, usually at the level of $P<0.001$ (Table 1). Only in the pT1+pT2 and adenocarcinoma mucinosum (ca muc) groups, statistically significant relationship between HIF-1 $\alpha$ and EPO expression was found at the level of $P<0.015$ and $<0.024$, respectively. It should be emphasized that these groups included a relatively small number of cancers, which could affect the statistical analysis (Table 1). 
Table 1. Comparison of the expression of HIF-1 $\alpha$ with the expression of EPO and EPOR in various groups of colorectal cancer. Spearman's correlation test

\begin{tabular}{|c|c|c|c|c|c|}
\hline \multirow{2}{*}{\multicolumn{2}{|c|}{$\begin{array}{l}\text { Groups of } \\
\text { patients }\end{array}$}} & \multicolumn{2}{|c|}{ HIF-1 $\alpha-$ EPO } & \multicolumn{2}{|c|}{ HIF-1 $\alpha-$ EPOR } \\
\hline & & \multirow{3}{*}{$\begin{array}{l}\mathbf{P} \\
<0.001 \\
<0.001\end{array}$} & \multirow{3}{*}{\begin{tabular}{|l|}
$\mathbf{r}$ \\
0.549 \\
0.499
\end{tabular}} & \multirow{3}{*}{$\begin{array}{l}\mathbf{P} \\
<0.001 \\
<0.001\end{array}$} & \multirow{3}{*}{\begin{tabular}{|l}
$\mathbf{r}$ \\
0.536 \\
0.509
\end{tabular}} \\
\hline $\begin{array}{l}\text { All patien } \\
n=125\end{array}$ & & & & & \\
\hline $\mathrm{N}$ & $\begin{array}{l}\mathrm{pN}(-) \\
\mathrm{n}=60\end{array}$ & & & & \\
\hline & $\begin{array}{l}\mathrm{pN}(+) \\
\mathrm{n}=65\end{array}$ & $<0.001$ & 0.587 & $<0.001$ & 0.544 \\
\hline \multirow[t]{2}{*}{$\mathrm{T}$} & $\begin{array}{l}\mathrm{pT} 1+2 \\
\mathrm{n}=12\end{array}$ & 0.015 & 0.678 & 0.001 & 0.845 \\
\hline & $\begin{array}{l}\mathrm{pT} 3+4 \\
\mathrm{n}=113\end{array}$ & $<0.001$ & 0.543 & $<0.001$ & 0.511 \\
\hline \multirow[t]{2}{*}{$\mathrm{G}$} & $\begin{array}{l}\mathrm{G} 2 \\
\mathrm{n}=87\end{array}$ & $<0.001$ & 0.488 & $<0.001$ & 0.426 \\
\hline & $\begin{array}{l}\mathrm{G} 3 \\
\mathrm{n}=38\end{array}$ & 0.003 & 0.475 & 0.001 & 0.521 \\
\hline \multirow[t]{2}{*}{ HP-type } & $\begin{array}{l}\text { Adenoca } \\
\mathrm{n}=107\end{array}$ & $<0.001$ & 0.542 & $<0.001$ & 0.491 \\
\hline & $\begin{array}{l}\text { Ca muc } \\
\mathrm{n}=18\end{array}$ & 0.024 & 0.529 & 0.005 & 0.645 \\
\hline \multirow[t]{2}{*}{ Sex } & $\begin{array}{l}\text { male } \\
\mathrm{n}=64\end{array}$ & $<0.001$ & 0.518 & $<0.001$ & 0.516 \\
\hline & $\begin{array}{l}\text { female } \\
\mathrm{n}=61\end{array}$ & $<0.001$ & 0.582 & $<0.001$ & 0.566 \\
\hline \multirow[t]{2}{*}{ Age } & $\begin{array}{l}\leq 60 \\
\mathrm{n}=43\end{array}$ & $<0.001$ & 0.643 & $<0.001$ & 0.612 \\
\hline & $\begin{array}{l}>60 \\
\mathrm{n}=82\end{array}$ & $<0.001$ & 0.497 & $<0.001$ & 0.493 \\
\hline \multirow[t]{2}{*}{ Location } & $\begin{array}{l}\text { rectum } \\
\mathrm{n}=57\end{array}$ & $<0.001$ & 0.554 & $<0.001$ & 0.532 \\
\hline & $\begin{array}{l}\text { colon } \\
\mathrm{n}=68\end{array}$ & $<0.001$ & 0.552 & $<0.001$ & 0.537 \\
\hline
\end{tabular}

HP-type - Histopathologic type, pT — depth of intramural growth, N - lymph node involvement, $\mathrm{G}$ - grading of cell differentiation; Adenoca — adenocarcinoma; Ca muc — adenocarcinoma

\section{Discussion}

HIF-1 is heterodimeric transcriptional factor that consists of two subunits: alpha $(\alpha)$ and beta $(\beta)$. HIF- $1 \alpha$ undergoes rapid degradation in normoxic conditions, so that proper transcriptional activity of the factor may take place in conditions of oxygen deficiency $[14,15]$. The HIF- $1 \alpha$-depending gene regulation is responsible for many different genetic expressions including EPO. Thus, high correlation can be expected between the expression of HIF- $1 \alpha$ and EPO in oxygen-deficient neoplastic tumors. We found a statistically significant correlation between HIF- $1 \alpha$ and EPO in all study subgroups. However, the values of correlation coeffi- cients $(r)$ varied among the respective anatomo-clinical subgroups and ranged between 0.5 and 0.6 . These values of correlation coefficients $(r)$ are relatively low for the theoretically very close relationships between the expressions of HIF- $1 \alpha$ and EPO. It should be emphasized that also the correlation of EPO and EPOR immunoexpression in colorectal cancers was at the same level $(\mathrm{r}=0.547 ; P<0.00001)$, which was presented in our earlier report [8]. However in the previous paper we had not examined correlations between EPO and EPOR in different anatomo-clinical subgroups of colorectal cancer patients.

We think that the fact that HIF- $1 \alpha$ was localized mainly in the cytoplasm is important for proper inter- 
pretation of our findings. The most expected location of immunohistochemical reaction would be a cell nucleus, which could suggest transcription activity of this factor, however, Yoshimura $\mathrm{H}$ et al. observed HIF- $1 \alpha$ expression in the cytoplasm and nucleus of the colorectal cancers cells [16]. The results reported by many authors indicate various location of HIF- $1 \alpha$ in the cell. Low-differentiated human pancreatic endocrine tumors (PET) show reaction for HIF- $1 \alpha$ in the cell nucleus, whereas more differentiated tumors are characterized by cytoplasmic reaction for HIF- $1 \alpha$ [17]. Similarly, Pansare et al. [18] and Giatromanolaki et al. [19] using a different types of HIF- $1 \alpha$ antibodies have shown that endometrial cancers exhibit nuclear and cytoplasmic location of HIF- $1 \alpha$.

Regarding some discrepancies in the reactivity of anti-EPOR C-20 antibody, it should be noted that Brown et al. [20] demonstrated that C20 antibody can be useful for immunohistochemical evaluation of EPOR. However, background staining that results from cross-reacting with HSP70, which is a heat shock protein and competes with EPOR in biding with C-20 antibody, seems to be a drawback of this antibody. In our study cytoplasm and cell membranes of colorectal cancer cells were stained with C-20 in granular fashion, similarly as described by Brown et al. [20]. The usefulness of C-20 antibody to detect EPOR has been confirmed in some recent reports [21, 22 ]. We have to remember too, that cancer cells can harbor numerous mutations, which might be responsible for cytoplasmic storage of some membranous proteins as in case of connexin 26 in colorectal cancerogenesis [23]. It has been shown that hypoxia limits maturation of cancer cells [24]. The expression of HIF- $1 \alpha$ can overcome these unfavorable for tumor growth effects of hypoxia via the activation of gene transcription and increased histological differentiation of cancer despite oxygen deficiency [25].

The co-expression of HIF- $1 \alpha$, EPO and EPOR was also noticed in non-small cell lung cancer, thus implicating possible significance of HIF- $1 \alpha$ in the induction of EPO and EPOR expression in pulmonary tumors [26]. Hypoxia-induced expression of EPO was distributed in a similar fashion to HIF-1 $\alpha$ in the vicinity of necrotic foci in endometrial cancer [27]. In our study, there was similar location of HIF- $1 \alpha$ and EPO staining in colorectal cancer tissues. Such a co-location of EPO and HIF-1 $\alpha$ expression suggested that the increased expression of EPO and HIF- $1 \alpha$ could be associated with cells death in hypoxic perinecrotic fields. Undoubtedly, complete elucidation of the significance of extranuclear accumulation of HIF- $1 \alpha$ and its co-expression with EPO and EPOR in colorectal cancer requires further studies.
The studies conducted in recent years have also demonstrated that EPO expression is not necessarily associated with the HIF- $1 \alpha / \beta$ complex. It has been found that apart from hypoxia also other factors modulate the intensity of EPO production, including hypoglycemia, elevated intracellular concentration of calcium ions, increased levels of insulin, estrogens and androgens [28, 29]. Little is known about the role that EPOR may play in cancer cells. High expression of EPO/EPOR was found in preinvasive and invasive carcinoma of the breast, renal cancer, colorectal cancer, primary liver cancer and other tumors [8, 30-35]. Probably, the enhanced EPO binding to its receptor EPOR in cancer cells triggers JAK2 and then STAT5 cascade [36]. However, it has to be noted that the studies of signal transduction pathways in cancer have been carried out mainly on cancer cell lines and their results do not always translate directly to the findings observed in vivo [36, 37]. It has been assumed that local paracrine action of erythropoietin activating the EPO/EPOR complex in cancer cells may promote tumor angiogenesis, especially in cancers characterized by the formation of a compact solid structure [33].

Despite a significant progress in our knowledge, the role of the EPO/EPOR complex in cancer cells still remains unclear, especially in association with other hypoxia-related proteins, such as HIF- $1 \alpha$ [38]. Although our present findings confirm the existence of a strong correlation of HIF-1alpha expression with the expression of EPO and EPOR it seems likely that in a significant number of tumors, the expressions of EPO and EPOR may not be fully controlled by HIF-1 $\alpha$ (in our CRC study values of correlation coefficients ranged from 0.5 to 0.6 ). The results seem to indicate complex biology of colorectal cancer and an important though not well known role of hypoxia and hypoxia-related proteins in the cancer progression. Further studies in this area of cancer biology are welcomed since the exogenous erythropoietin (rHuEpo) has been increasingly used in the treatment of cancer-associated anemia [39].

\section{References}

1. Ke Q, Costa M. Hypoxia-inducible factor-1 (HIF-1). Mol Pharmacol. 2006;70:1469-1480.

2. Lee JW, Bae SH, Jeong JW, Kim SH and Kim KW. Hypoxia-inducible factor (HIF-1) alpha: its protein stability and biological functions. Exp Mol Med. 2004;36:1-12.

3. Zagorska A, Dulak J. HIF-1: the knowns and unknowns of hypoxia sensing. Acta Biochim Pol. 2004;51:563-585.

4. D Bels D, Corazza F, Germonpré P and Balestra C. The normobaric oxygen paradox: A novel way to administer oxygen as an adjuvant treatment for cancer? Med Hypotheses. 2011;76:467-470.

5. Fisher JW. Erythropoietin: physiology and pharmacology update. Exp Biol Med. 2003;228:1-14. 
6. Broxmeyer HE. Erythropoietin: multiple targets, actions, and modifying influences for biological and clinical consideration. J Exp Med. 2013;210:205-208.

7. Farrell F, Lee A. The erythropoietin receptor and its expression in tumor cells and other tissues. Oncologist. 2004;9:18-30.

8. Chabowska AM, Sulkowska M, Chabowski A, Wincewicz A, Koda M and Sulkowski S. Erythropoietin and erythropoietin receptor in colorectal cancer. Int J Surg Pathol. 2008;16:269-276.

9. Lee WY, Huang SC, Hsu KF, Tzeng CC, Shen WL. Roles for hypoxia-regulated genes during cervical carcinogenesis: somatic evolution during the hypoxia-glycolysis-acidosis sequence. Gynecol Oncol. 2008;108:377-384.

10. Lee AS, Kim DH, Lee JE et al. Erythropoietin induces lymph node lymphangiogenesis and lymph node tumor metastasis. Cancer Res. 2011;71:4506-4517.

11. Volgger B, Kurz K, Zöschg K et al. Importance of erythropoetin receptor expression in tumour tissue for the clinical course of breast cancer. Anticancer Res. 2010;30:3721-3726.

12. Wincewicz A, Sulkowska M, Koda M and Sulkowski S. Clinicopathological significance and linkage of the distribution of HIF-1alpha and GLUT-1 in human primary colorectal cancer. Pathol Oncol Res. 2007;13:15-20.

13. Wincewicz A, Sulkowska M, Koda M, Leśniewicz T, Kanczuga-Koda L and Sulkowski S. STAT3, HIF-1alpha, EPO and EPOR - signaling proteins in human primary ductal breast cancers. Folia Histochem Cytobiol. 2007;45:81-86.

14. Wang GL, Jiang BH, Rue EA and Semenza GL: Hypoxia-inducible factor 1 is a basic-helix-loop-helix-PAS heterodimer regulated by cellular $\mathrm{O}_{2}$ tension. Proc Natl Acad Sci USA. 1995;92:5510-5514.

15. Wood SM, Wiesener MS, Yeates KM et al. Selection and analysis of a mutant cell line defective in the hypoxia-inducible factor-1 alpha-subunit (HIF-1alpha). Characterization of HIF- $1 \alpha$-dependent and -independent hypoxia-inducible gene expression. J Biol Chem. 1998;273:8360-8368.

16. Yoshimura H, Dhar DK, Kohno H et al. Prognostic impact of hypoxia-inducible factors $1 \alpha$ and $2 \alpha$ in colorectal cancer patients: correlation with tumor angiogenesis and cyclooxygenase-2 expression. Clin Cancer Res. 2004;10:8554-8560.

17. Couvelard A, O'Toole D, Turley H et al. Microvascular density and hypoxia-inducible factor pathway in pancreatic endocrine tumours: negative correlation of microvascular density and VEGF expression with tumour progression. $\mathrm{BrJ}$ Cancer. 2005;92:94-101.

18. Pansare V, Munkarah AR, Schimp V et al. Increased expression of hypoxia-inducible factor $1 \alpha$ in type I and type II endometrial carcinomas. Modern Pathology. 2007;20:35-43.

19. Giatromanolaki A, Fiska A, Pitsiava D et al. Erythropoietin receptors in endometrial carcinoma as related to HIF1 $\alpha$ and VEGF expression. In vivo. 2009;23:699-704.

20. Brown WM, Maxwell P, Graham AN et al. Erythropoietin receptor expression in non-small cell lung carcinoma: a question of antibody specificity. Stem Cells. 2007;25:718-722.

21. Ribatti D, Marzullo A, Gentile A et al. Erythropoietin/ erythroproietin receptor system is involved in angiogenesis in human hepatocellular carcinoma. Histopathology. 2007;50:591-596.
22. Ribatti D, Poliani PL, Longo V et al. Erythropoietin/erythroproietin receptor system is involved in angiogenesis in human neuroblastoma. Histopathology. 2007;50:636-641.

23. Kanczuga-Koda L, Sulkowska S, Koda M, Sulkowska M. Alterations in connexin 26 expression during colorectal carcinogenesis. Oncology. 2005;68:217-222.

24. Garofalo C, Koda M, Cascio S et al. Increased expression of leptin and the leptin receptor as a marker of breast cancer progression: possible role of obesity-related stimuli. Clin Cancer Res. 2006;12:1447-1453.

25. Brown LM, Cowen RL, Debray $\mathrm{C}$ et al. Reversing hypoxic cell chemoresistance in vitro using genetic and small molecule approaches targeting hypoxia inducible factor-1. Mol Pharmacol. 2006;69:411-418.

26. Dagnon K, Pacary E, Commo F et al. Expression of erythropoietin and erythropoietin receptor in non-small cell lung carcinomas. Clin Cancer Res. 2005;11:993-999.

27. Acs $G, X u X, C h u C, A c s ~ P$, Verma A. Prognostic significance of erythropoietin expression in human endometrial carcinoma. Cancer. 2004;100:2376-2386.

28. Jelkmann W. Physiology and pharmacology of erythropoietin. Transfus Med Hemother. 2013;40:302-309.

29. Elliott S, Sinclair AM. The effect of erythropoietin on normal and neoplastic cells. Biologics. 2012;6:163-189.

30. Wincewicz A, Baltaziak M, Kanczuga-Koda L, Koda M, Sulkowska U, Sulkowski S. GLUT1 and Bcl-xL in relation to erythropoietin in human colorectal adenocarcinomas. Hepatogastroenterology. 2010;57:741-745.

31. Westenfelder C, Baranowski RL. Erythropoietin stimulates proliferation of human renal carcinoma cells. Kidney Int. 2000;58:647-657.

32. Mohyeldin A, Lu H, Dalgard C et al. Erythropoietin signaling promotes invasiveness of human head and neck squamous cell carcinoma. Neoplasia. 2005;7:537-543.

33. Ribatti D, Marzullo A, Nico B, Crivellato E, Ria R, Vacca A. Erythropoietin as an angiogenic factor in gastric carcinoma. Histopathology. 2003;42:246-250.

34. Yasuda Y, Fujita Y, Matsuo T et al. Erythropoietin regulates tumour growth of human malignancies. Carcinogenesis. 2003;24:1021-1029.

35. Yin D, Kawabata H, Tcherniamtchouk O, Huynh T, Black KL, Koeffler HP. Glioblastoma multiforme cells: expression of erythropoietin receptor and response to erythropoietin. Int J Oncol. 2007;31:1193-1198.

36. Lai SY, Childs EE, Xi S et al. Erythropoietin-mediated activation of JAK-STAT signaling contributes to cellular invasion in head and neck squamous cell carcinoma. Oncogene. 2005;24:4442-4449.

37. Wu XY, Fu ZX, Wang XH, Shen W. Identification of differential proteins in colon cancer SW480 cells with HIF1 $\alpha$ silence by proteome analysis. Neoplasma. 2010;57:299-305.

38. Gombos Z, Danihel L, Repiska V, Acs G, Furth E. Expression of erythropoietin and its receptor increases in colonic neoplastic progression: the role of hypoxia in tumorigenesis. Indian J Pathol Microbiol. 2011;54:273-278.

39. Wang L, Li HG, Xia ZS, Wen JM, Lv J. Prognostic significance of erythropoietin and erythropoietin receptor in gastric adenocarcinoma. World J Gastroenterol. 2011;17:3933-3940.

Submitted: 11 November, 2013

Accepted after reviews: 30 December, 2013 